\title{
Uptake of acid black 210 dye by organo-montmorillonite clay minerals
}

\author{
Cristina Volzone a, ${ }^{*}$, Norma Gallegos b, Carlos Cantera c and Alberto Greco c \\ a Centro de Tecnología de Recursos Minerales y Cerámica (CETMIC), Centro Científico Tecnológico-Consejo Nacional de Investigaciones Científicas y Tecnológicas- \\ La Plata, Comisión de Investigaciones Científicas de la Provincia de Buenos Aires, M. B. Gonnet, 1897, Argentina \\ b Centro de Investigación y Desarrollo en Ciencias Aplicadas (CINDECA), Centro Científico Tecnológico-Consejo Nacional de Investigaciones Científicas y \\ Tecnológicas- La Plata, Facultad de Ingeniería, Universidad Nacional de La Plata, La Plata, 1900, Argentina \\ c Centro de Investigación y Desarrollo del Cuero (CITEC)-Instituto Nacional de Tecnología Industrial, Comisión de Investigaciones Científicas de la Provincia de \\ Buenos Aires, M. B. Gonnet, 1897, Argentina
}

*Corresponding author at: Centro de Tecnología de Recursos Minerales y Cerámica (CETMIC), Centro Científico Tecnológico-Consejo Nacional de Investigaciones Científicas y Tecnológicas- La Plata, Comisión de Investigaciones Científicas de la Provincia de Buenos Aires, M. B. Gonnet, 1897, Argentina.

Tel.: +54.221.4840247; fax: +54.221.4710075. E-mail address: cvolzone@cetmic.unlp.edu.ar (C. Volzone).

\section{ARTICLE INFORMATION}

Received: 27 June 2013

Accepted: 22 July 2013

Online: 31 December 2013

\section{KEYWORDS}

\section{Clays}

Dyes

Adsorption

IR spectroscopy

$\mathrm{X}$-ray diffraction

UV/Vis spectroscopy

\section{Introduction}

Dye effluents from diverse industries can originate pollutants in aquatic systems. Environmental legislations give concentration limitations and generally the effluents should be decontaminated. Most commercial systems use activated carbon filters due to their high adsorption capacity, however their use in large scale, remains limited due to their high cost [1]. In order to reduce the cost of treatment, many studies are being carried out around the world to find effective adsorbents and low cost.

A review of the literature on these non-conventional adsorbents indicates that the adsorption capacity of natural clays, activated or modified can be very high, with a much lower cost [2-9].

Clays are natural minerals abundant in nature. Montmorillonite is clay mineral tetrahedral-octahedraltetrahedral (T-O-T or 2:1) layers phyllosilicate type: two $\mathrm{Si}$ tetrahedral sheets are separated by one Al octahedral sheet (T$\mathrm{O}$-T). The isomorphic substitutions in the sheets originate deficits of positive electric charges. These charges are balanced by exchangeable cations in interlayer positions (Figure 1). The clay minerals show hydrophilic characteristics, nevertheless, it is possible to convert in organophylic by intercalating organic species within the interlayer sites of the clay. In this condition, the clay can interact with anionic dyes.

The aim of this study was to evaluate the retention of the acid black 210 , one commercial anionic dye presents in tanning industry effluent, by organo-montmorillonite. The evaluation of retentions was obtained by UV-visible spectra. According to a previous paper [10] it is recommendable to analyze the equilibrium solution in the complete wavelength range, due to possible modifications of the bands by formation of aggregates of dye molecules, the influence of the clay, color changes, etc. Consequently, incorrect results of the adsorptive capacity of the solid can be obtained.

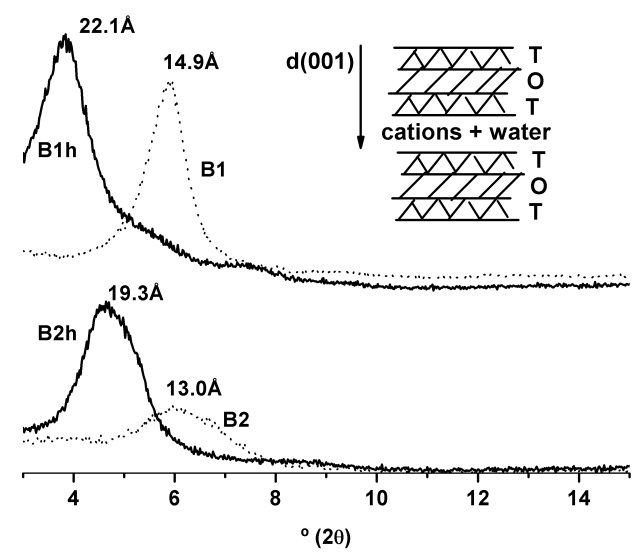

Figure 1. Basal spacing, d(001), of samples and scheme of clay mineral T-O-T layer.

\section{Experimental}

\subsection{Instrumentation}

The X-ray diffraction equipment was a Philips 3020 Goniometer with PW 3710 Controller, $\mathrm{Cu} \mathrm{K} \alpha$ radiation $(\lambda=$ 
$1.5405 \AA$ ) , and Ni filter at $40 \mathrm{kV}$ and $20 \mathrm{~mA}$. The patterns were obtained by scanning at $1^{\circ}(2 \theta) / \mathrm{min}$ between 3 and $15^{\circ}(2 \theta)$.

The infrared spectra were recorded with Spectrum One Perkin Elmer equipment from 4000 to $380 \mathrm{~cm}^{-1}$. The samples were dispersed in $\mathrm{KBr}(1 \%$ mass) and compacted in a thin pellet form.

\subsection{Synthesis}

Two montmorillonite clay minerals from Apache County, Arizona, USA and Wyoming, USA named as B1 and B2 were used in this paper. Montmorillonites are phyllosilicate types 2:1 layer constituted by two sheets of silicon tetrahedral separated by one sheet of aluminium octahedral. The isomorphic substitutions of silicon by aluminium and/or aluminium by magnesium originate deficit charges, which are compensated by cations that are situated in interlayer spacing, Figure 1.

The half-unit cell compositions calculated in a previous paper [11] are shown in Table 1.

Table 1. Structural half-unit cell composition *

\begin{tabular}{llllll}
\multirow{2}{*}{ Bentonite } & \multicolumn{4}{l}{ Tetrahedral sheet } & \multicolumn{4}{l}{ Octahedral sheet } \\
\cline { 2 - 6 } & $\mathbf{S i}^{4+}{ }_{\mathrm{IV}}$ & $\mathbf{A l}^{3+}{ }_{\mathrm{IV}}$ & $\mathbf{A l}^{3+}{ }_{\mathrm{VI}}$ & $\mathbf{F e}^{3+}$ & $\mathbf{M g}^{2+}$ \\
\hline $\mathrm{B} 1$ & 3.94 & 0.06 & 1.36 & 0.06 & 0.60 \\
$\mathrm{~B} 2$ & 3.91 & 0.09 & 1.61 & 0.13 & 0.26 \\
\hline${ }^{*}{ }^{4 i^{4+} \mathrm{IV}}$ : Silica in IV coordination; $\mathrm{Al}^{3+}{ }_{\mathrm{IV}}:$ Aluminum in IV coordination; $\mathrm{Al}^{3+}{ }_{\mathrm{VI}}:$
\end{tabular}

Aluminum in VI coordination.

Hexadecylpyridinium (HDP+) cation was used to prepare organo-montmorillonites. Aqueous solution hexadecylpyridinium chloride salts was added to montmorillonite suspensions and stirred during 24 hours. The solids were washed to remove excess salts, stored at room temperature and named as B1h and B2h.

The amount of organic cation added to the montmorillonites was one time the cation exchange capacity (CEC) of such clay minerals. The CEC of the B1 and the B2 bentonites were 110 and $97 \mathrm{meq} / 100 \mathrm{~g}$, respectively. The higher CEC of B1 is due to higher isomorphous substitution in the structure, in which $\mathrm{Mg}^{2+}$ replaced to $\mathrm{Al}^{3+}$ in the octahedral sheet.

The anionic dye solution (B) was prepared by using acid black 210 provided by CITEC (Centro de Investigacion y Desarrollo del Cuero). The concentration of the dye solution used in this study was $50 \mathrm{mg} / \mathrm{L}$.

The retention experiments were carried out in a batch system by placing the organo-montmorillonite in contact with a $50 \mathrm{mg} / \mathrm{L}$ acid black solution. The solid/liquid ratio was 1.5 $\mathrm{wt} / \mathrm{v} \%$. After two days in contact the supernatant was separated an analyzed. The obtained solids after uptake of dye were named $\mathrm{B} 1 \mathrm{hB}$ and $\mathrm{B} 2 \mathrm{hB}$. The relative acid black retention by organo-montmorillonite was calculated by the difference between the initial concentration of acid black solution (B) and the same solution after contacted solid, by using a HewlettPackard Model 8453 spectrophotometer reading absorbance at $463 \mathrm{~nm}$.

\section{Results and discussion}

\subsection{Organo-montmorillonite characterization}

The interlayer spacing of montmorillonites was modified after treatments. The interlayer spacing, $d(001)$, refers to the distance between a lamella and the next, i.e. includes the thickness of the T-O-T (2:1) layer structure and spacing in which the exchangeable cations are situated (Figure 1).

The intercalation of montmorillonites with HDP cations resulted in an increase in basal spacing of the B1 and B2 clay minerals from 14.9 and $13.0 \AA$ to 22.1 and $19.3 \AA$, respectively (B1h, B2h), Figure 1. $\mathrm{HDP}^{+}$produces larger basal spacing due to its arrangement in the interlayer. Lagaly [12] mentioned that $n$ alkylpyridinium cations (as HDP) occur as a bilayer. The higher $\mathrm{d}(001)$ spacing of the, B1h, than B21h could be attributed to different ordering of the organic substance in interlayer position due to greater $\mathrm{CEC}$ of the $\mathrm{B} 1$ in relation to $\mathrm{B} 2$ montmorillonite.

Infrared spectra of the B1and B2 pristines (Figure 2a and 2b) showed bands at 3622 (Al-Mg-OH stretching), 3430 (H-O-H stretching), 1110 (Si-O-Si stretching), 1035 (Si-O-Si stretching), 916 ( $\mathrm{Al}_{2} \mathrm{OH}$ bending), $882 \mathrm{~cm}^{-1}$ (Al-Fe-OH stretching, only for $\mathrm{B} 2$ due to more amount of Fe percentage presents in structure layer ), 837 (Al-Mg-OH bending), 519 (Si-O-Al bending) and $463 \mathrm{~cm}^{-1}$ (Si-O-Si bending), typical of montmorillonite clay minerals [13]. After conversion to organo-montmorillonite (B1h and B2h), new bands were observed, corresponding to principal bands of the HDP cation, because the natural cations in interlayer position of the montmorillonites were replaced. The bands at 2918 and $2849 \mathrm{~cm}^{-1}$ are typical of bond $\mathrm{C}-\mathrm{H}$ methylene asymmetric and symmetric mode bond, respectively [14]. The wavenumber of $\mathrm{C}-\mathrm{H}$ methylene asymmetric band is sensitive to the ordering of carbon in the organic chain [15]. If the band of stretching asymmetrical C-H methylene is shifted to higher wavenumber and widens, it would indicate a tendency to disorder of the organic cation chain, such as it was observed for B2h sample, where the band was situated at $2926 \mathrm{~cm}^{-1}$, whereas for B1h the value at $2918 \mathrm{~cm}^{-1}$ indicated order (Figure 2a). The bands at 1473 and $723 \mathrm{~cm}^{-1}$ are assigned to methylene scissoring and methylene rocking modes, respectively. B1h sample showed bands situated at 1470,1488 and at 723, Figure 2b. According to He et al. [14] the presence of doublets at 1467 and $1473 \mathrm{~cm}^{-1}$ by using FTIR spectroscopy with $\mathrm{KBr}$ pressed disk technique is indicative of conformational ordering of the chain within the clay interlayer. In Figure $2 b$, the doublets at $1470-1488 \mathrm{~cm}^{-1}$ of B1h sample may be indicate better ordering of the $\mathrm{HDP}^{+}$in interlayer position than that in $\mathrm{B} 2 \mathrm{~h}$ sample.

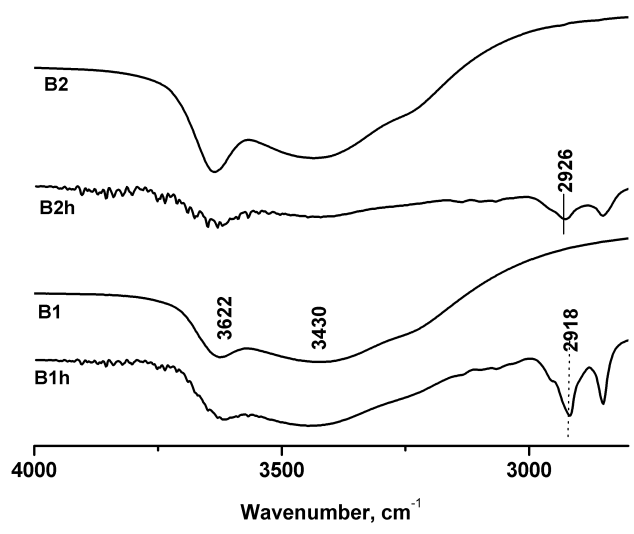

(a)

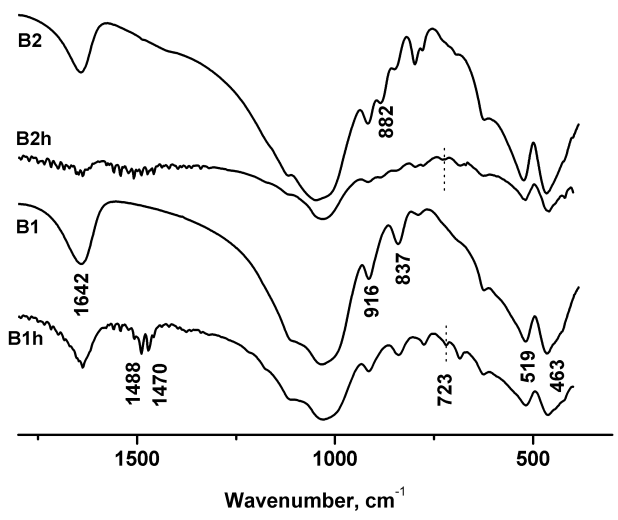

(b)

Figure 2. Infrared spectra of B1 and B2 before and after HDP treatment. (a) $4000-2800 \mathrm{~cm}^{-1}$ range, (b) $2300-300 \mathrm{~cm}^{-1}$ range. 
The presence of HDP cation affected the OH-stretching of water $\left(3430 \mathrm{~cm}^{-1}\right)$, Figure $2 \mathrm{a}$, and adsorbed water $\mathrm{H}-\mathrm{O}-\mathrm{H}$ bending $\left(1642 \mathrm{~cm}^{-1}\right)$, Figure $2 \mathrm{~b}$, of the organo clays. The intensity of the bands at 3430 and $1642 \mathrm{~cm}^{-1}$ were reduced after intercalation of organic cation in interlayer position, then, such organic cation reduced the water content as in similar form than other type of organic cations [16]. Subsequently, B1h presented better ordering of the HDP cation in interlayer position and containing more water molecule than B2h sample.

The infrared spectrum of the acid black 210 dye in Figure 3a shows several bands, nevertheless, the principals are situated at $3430 \mathrm{~cm}^{-1}$, attributed to intramolecular hydrogen bonding aromatic-OH and O-H stretching; at 2929 and 2853 $\mathrm{cm}^{-1}$ for $\mathrm{C}-\mathrm{H}$ stretching, and at $1480 \mathrm{~cm}^{-1}-\mathrm{CH}_{2}$ scissoring.
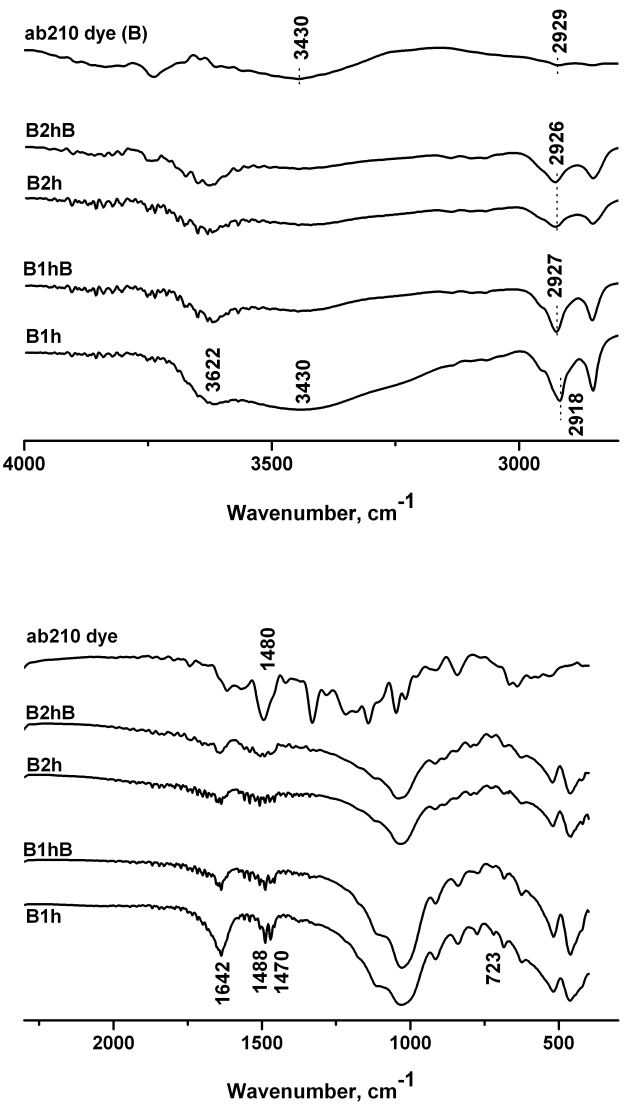

(b)

Figure 3. Infrared spectra of organo-montmorillonite (B1h and B2h) before and after contacting with B solution. a) $4000-2800 \mathrm{~cm}^{-1}$ range, b) 2300-300 $\mathrm{cm}^{-1}$ range.

The typical bands of acid black dye were not visible in organo montmorillontes after contacted with the dye solution (B1hB and B2hB) as shown in Figure 3a and b. However, the bands at $3430 \mathrm{~cm}^{-1}$ and the doublet at $1470-1488 \mathrm{~cm}^{-1}$ of the organo montmorillonite were reduced. As such doublet can be related with ordering of the HDP cation in interlayer position; the results indicated that the presence of the dye reduced such ordering, in higher amount for $\mathrm{B} 2 \mathrm{hB}$. Then, the presence of organic cation and dye affected the $\mathrm{OH}-$ and $\mathrm{H}-\mathrm{O}-\mathrm{H}$ water, and on the other hand, the dye influenced the ordering of HPD cation in interlayer position in higher degree for B2h sample.

Finally, the infrared analysis (Figures 2 and 3) indicated that the bands corresponding to $\mathrm{Si}-\mathrm{O}-\mathrm{Si}$ stretching vibration, $\mathrm{Al}-\mathrm{Al}-\mathrm{OH}, \mathrm{Mg}-\mathrm{Al}-\mathrm{OH}, \mathrm{Si}-\mathrm{O}-\mathrm{Al}^{\mathrm{IV}}$ and $\mathrm{Si}-\mathrm{O}-\mathrm{Si}$ groups of the montmorillonite clay mineral, remained unaffected after both: organo cation HDP and the acid black molecule treatments.

\subsection{Retention of acid black dye}

Figure 4 shows the complete UV-visible spectrum of the anionic acid black $50 \mathrm{mg} / \mathrm{L}$, B solution, before and after contact with organo-montmorillonites. Three bands in the visible spectrum are characteristics of acid black 210 solutions, at 316 , $463602 \mathrm{~nm}$ wavelength. The use of the complete spectrum, not common to see in published papers, allow a better evaluation because possible modifications or changes of the characteristic bands of the dye in solutions after contacted solids can be occur.

The initial intensity of the dye bands decreased around 80$90 \%$ after its contacting with organo-montmorillonites. For evaluating the uptake of dye by the solids, it was selected the band at $463 \mathrm{~nm}$, analyzing the absorbance of such band before and after contact with the adsorbent.

The amount of retained acid black by B1h and B2h organo montmorillonites were 25.3 and $29.8 \mathrm{mg} / \mathrm{g}$, respectively.

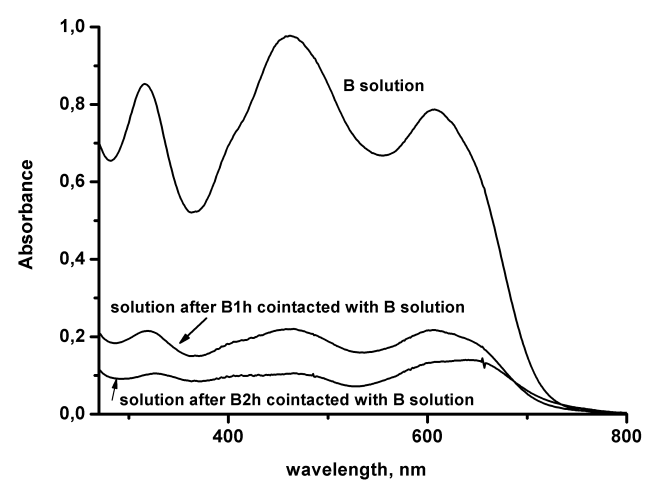

Figure 4. Evolution of Acid Black 120, 50 ppm solution UV-visible spectrum before and after contact with natural and organo-montmorillonite.

\section{Conclusion}

Organo-montmorillonites prepared by exchangeable organic HDP cation showed significant level of anionic Acid Black 210 retention (a dye used in tanning industry). The interlayer spacings of the analyzed montmorillonites increased from 13.0-14.9 $\AA$ to 19-22 $\AA$ after HDP treatment. FTIR and XRD analyses demonstrated that the ordering of the HPD cation in montmorillonie was better when the CEC value was higher. The uptake of acid black from solution was better by using HPD-montmorillonite with disordered arrangement of HPD cation in interlayer spacing of the montmorillonite. In this work, we demonstrated that natural clay minerals, such as montmorillonite, abundant in nature and low cost can be used as precursor for obtaining organo-clay adsorbent in remediation process for waste tanning.

\section{Acknowledgements}

We wish to acknowledge CONICET for their financial support (PIP02100) as well CICPBA and INTI institutions.

\section{References}

[1]. Crini, G. Bioresource Technol. 2006, 97, 1061-1085.

[2]. Churchman, G. J. Appl. Clay Sci. 2002, 21, 177-189.

[3]. Ozcan, A. S.; Erdem, B.; Ozcan, A. J. Colloid Interf. Sci. 2004, 280, 44-54.

[4]. Ozcan, A. S.; Ozcan, A. J. Colloid Interf. Sci. 2004, 276, 39-46.

[5]. Tsai, W. T.; Chang, Y. M.; Lai, C. W.; Lo, C. C. Appl. Clay Sci. 2005, 29, 149-154.

[6]. Alexandros, M. R.; Vassiliadis, A. Micropor. Mesopor. Mat. 2008, 116 732-740.

[7]. Wang, L.; Wang, A. J. Hazard Mater. 2008, 160, 173-180.

[8]. Benguella, B. ; Yacouta-Nour, A. CR. Acad. Sci. II C 2009, 12, 762-771. 
[9]. Lian, L.; Guo, L.; Guo, C. J. Hazard Mater. 2009, 161, 126-131.

[10]. Bailly, J.; Volzone, C.; Cantera, C.; Greco, A. XXXI IULTCS (International Union of Leather Technologisys and Chemist Societies) Congress, Valencia (Spain), 2011, 1-8

[11]. Volzone, C.; Garrido, L. B. J. Environ. Manage. 2008, 88, 1640-1648.

[12]. Lagaly, G. Philos. T. R. Soc. A 1984, 311, 315-332.

[13]. Farmer, V. C. Clay Miner. 1968, 7, 373-387.

[14]. He, H.; Frost L. R.; Zhu, J. Spectrochim. Acta A 2004, 60, 2853-2859

[15]. Li, Z.; Wei-Teh, J.; Hanlie, H. Spectrochim. Acta A 2008, 71, 1525-1534.

[16]. Vidal, N. C.; Volzone, C. Anais do $6^{\circ}$ Encontro Brasileiro sobre Adsorcao, Maringa (Brasil) 2006, CD-ROM 1, 23, 1-5. 